\title{
A VALIDATED STABILITY-INDICATING REVERSE-PHASE HIGH-PERFORMANCE LIQUID CHROMATOGRAPHY METHOD FOR DACLATASVIR, IDENTIFICATION AND CHARACTERIZATION OF DEGRADATION PRODUCTS USING LC-ESI-QTOF-MS
}

SNEHAL V WARGHADE ${ }^{1 *}$, KAILASH G BOTHARA ${ }^{2}$

${ }^{1}$ Department of Pharmaceutical Chemistry, STES's, Smt. Kashibai Navale College of Pharmacy, Kondhwa, Savitribai Phule Pune University, Pune, Maharashtra, India. ${ }^{2}$ Department of Pharmaceutical Chemistry, STES's, Sinhgad Institute of Pharmacy, Narhe, Pune, Maharashtra, India. Email: snehalwarghade@gmail.com

Received: 11 March 2019, Revised and Accepted: 11 April 2019

ABSTRACT

Objective: The objective of this study was to report the stability of antiviral drug, daclatasvir (DCV) based on the information obtained from forced degradation studies and characterization of degradation products (DPs) by tandem mass spectrometry (MS/MS) analysis.

Methods: Chromatographic separation was achieved on Shimadzu liquid chromatography (LC) 20 AD high-performance LC system with photodiode array detector having Kromasil C18 $(250 \mathrm{~mm} \times 4.6 \mathrm{~mm} \times 5 \mu \mathrm{m})$ with isocratic elution of a mobile phase composed of ammonium acetate buffer (pH 4.5) and acetonitrile in a ratio of 50:50 at $315 \mathrm{~nm}$. The drug was subjected to forced hydrolytic, oxidative, photolytic, and thermal stress in accordance with the ICH guideline Q1A $\left(\mathrm{R}^{2}\right)$. The drug showed degradation under acidic and basic hydrolytic conditions by forming two DPs. The DPs were characterized using LCMS/MS studies and the pathways of fragmentation are proposed. Validation of the developed method was carried out in accordance with ICH guidelines.

Results: Two DPs were identified, DP-1 as (S)-1-((S)-2-(5-(4'-(2-((S)-1-((S)-2-((methoxycarbonyl)amino)-3-methylbutanoyl)pyrrolidin-2-yl)-1Himidazol-5-yl)-[1,1'-biphenyl]-4-yl)-1H-imidazol-2-yl)pyrrolidin-1-yl)-3-methyl-1-oxobutan-2-aminium and DP-2 as (S)-2-(5-(4'-(2-((S)-1-((S)-2((methoxycarbonyl)amino)-3-methylbutanoyl)pyrrolidin-2-yl)-1H-imidazol-5-yl)-[1,1'-biphenyl]-4-yl)-1H-imidazol-2-yl)pyrrolidin-1-ium.

Conclusion: The method proved to be simple, accurate, precise, specific, robust, and less time consuming and can be applied for the determination of DCV in bulk and marketed formulation.

Keywords: Daclatasvir, Stress degradation, Characterization, Degradation products, Liquid chromatography-mass spectrometry.

(C) 2019 The Authors. Published by Innovare Academic Sciences Pvt Ltd. This is an open access article under the CC BY license (http://creativecommons. org/licenses/by/4. 0/) DOI: http://dx.doi.org/10.22159/ajpcr.2019.v12i5.32829

\section{INTRODUCTION}

The quality of the drugs comprehends the potency, uniformity, purity, pharmacological action, stability, etc. Therefore, it becomes essential for the manufacturer to maintain the quality and produce effective, safe, and non-toxic forms of drugs by developing newer analytical methods [1]. The present ICH stability testing guideline requires reporting, identification, and characterization of the degradation products (DPs) [2]. In parallel, the ICH guidelines on impurities [3] require characterization of all DPs formed in drug products at $\geq 0.1 \%$. However, as DPs generated during storage may be at very low levels $(\sim 0.1-0.5 \%, \mathrm{w} / \mathrm{w})$, stress studies are suggested to generate them in higher amounts [4]. Therefore, today, focus is on techniques that allow the characterization of very low quantities of DPs, against the conventional process of isolation and spectral analysis, which is tedious and time consuming. Tandem mass spectrometry (MS/ MS) (multistage MS) and liquid chromatography (LC) coupled with MS (LC-MS, LC-MS/MS) becoming the most versatile techniques for characterization of pharmaceutical DPs and impurity profiling [5].

Daclatasvir (DCV), a non-structural 5A protein inhibitor, combined with sofosbuvir, is indicated for adult patients with chronic HCV genotype 3 regardless of treatment or cirrhosis status [6]. DCV is a white to yellow crystalline solid having chemical formula $\mathrm{C}_{40} \mathrm{H}_{50} \mathrm{~N}_{8} \mathrm{O}_{6}$. Its structural formula is given in Fig. 1.

According to literature survey, there are only few reports on the use of stability-indicating reverse-phase high-performance LC (RPHPLC) method for the study of degradation behavior of DCV [7-10]. Recently, isolation and characterization of degraded products have been reported [11]. There are no reports available on characterization of alkaline hydrolytic DP to the best of our knowledge. Hence, the objective of the current study was to develop stability-indicating RPHPLC method for estimation of DCV in tablet formulation to decrease the retention time and run time of analysis.

The present manuscript describes the (1) degradation behavior of DCV under hydrolysis (acid, base, and neutral), oxidation, photolysis, and thermal stress conditions, (2) separate the drug and its DPs on a reversed-phase C18 column, LC method conditions were optimized, (3) method validation, (4) characterization of DPs, and (5) proposed fragmentation pathway of DPs using LC-MS/MS.

\section{METHODS}

Chemicals and reagents

Pure sample of DCV was purchased from Taj Mahal Vision Chemicals Pvt. Ltd., Mumbai, India. Analytical reagent grade ammonium acetate, glacial acetic acid, orthophosphoric acid, hydrochloric acid ( $\mathrm{HCl}$ ), sodium hydroxide $(\mathrm{NaOH})$, and hydrogen peroxide $\left(\mathrm{H}_{2} \mathrm{O}_{2}\right)$ were purchased from HiMedia Laboratories Pvt., Ltd., Mumbai, India. LC-MS grade methanol and acetonitrile were procured from Sigma-Aldrich, Bengaluru, India. HPLC-grade water was obtained from Millipore, Bedford, MA, USA, to prepare all solutions.

\section{Instrumentation}

HPLC

The chromatographic analysis was performed on LC $20 \mathrm{AD}$ separation module HPLC system (Shimadzu Pvt., Ltd., Mumbai) consisting 
of quaternary gradient pump with an in-line degasser, a column compartment with temperature control and a photodiode array (PDA) detector. Chromatography data were acquired using LC solutions software. To dissolve the samples, an ultrasonicator SI 1432 (Wensar Weighing Scales Ltd., Mumbai) was used. LI $120 \mathrm{pH}$ meter (Elico Ltd., Hyderabad) was used. A precision water bath equipped with MV controller (i-therm, Biomedica, India) capable of controlling the temperature within $\pm 1^{\circ} \mathrm{C}$ was used for generating hydrolytic DPs. Thermal stress studies were carried out using a hot air oven Biotechnics BTI-20D, Mumbai, India). For photodegradation study, ultraviolet (UV) chamber used was to be of BIT make (model no. 49).

\section{$M S$}

LC-MS studies were carried out on an Agilent G1329B LC instrument (Agilent Technologies, USA) hyphenated to a quadrupole time-of-flight (Q-TOF) MS (Q-TOF LC-MS G6540B series, Agilent Technologies, USA) coupled with an electrospray ionization (ESI) source. The MS data were acquired using MassHunter Workstation software. The typical operating source conditions for MS scan of DCV and its DPs in positive ESI mode were optimized as follows: Fragmentor voltage was set at $170 \mathrm{~V}$, the capillary voltage at $3500 \mathrm{~V}$, skimmer at $60 \mathrm{~V}$, and nitrogen was used as the drying $\left(320^{\circ} \mathrm{C}, 10 \mathrm{~L} / \mathrm{min}\right)$ and nebulizing ( $\left.45 \mathrm{psi}\right)$ gas. All the spectra were recorded at an average of 20-25 scans.

\section{Preparation of buffer}

About $3.85 \mathrm{~g}$ of ammonium acetate and $2.8 \mathrm{ml}$ of glacial acetic acid were added to $500 \mathrm{ml}$ volumetric flask and volume was made with double distilled water. The $\mathrm{pH}$ (4.5) was adjusted with orthophosphoric acid. The solution was filtered through $0.45 \mu$ membrane filter and then sonicated in a sonicator for $15 \mathrm{~min}$

\section{Preparation of mobile phase}

Buffer (50\%) and acetonitrile (50\%) were mixed and then filtered through $0.45 \mu$ filter under vacuum filtration and degassed in an ultrasonicate water bath for $15 \mathrm{~min}$.

\section{Method validation}

The analytical method was validated with respect to parameters such as specificity, linearity, limit of quantification (LOQ), limit of detection (LOD), precision, accuracy, and robustness [12-14].

\section{Stress decomposition studies}

To determine the stability-indicating ability of developed HPLC method, in-house tablet formulation powder, active pharmaceutical ingredient powder, and placebo sample were stressed under various conditions as per ICH guidelines. A stock solution was prepared by dissolving $60 \mathrm{mg}$ DCV in $100 \mathrm{ml}$ volumetric flask with mobile phase to get concentration of $600 \mu \mathrm{g} / \mathrm{ml}$. In all cases, $1 \mathrm{ml}$ of an aliquot of the above stock solution was transferred into a $10 \mathrm{ml}$ volumetric flask. Added $3 \mathrm{ml}$ of stressor to it. All hydrolytic studies were conducted at $80^{\circ} \mathrm{C}$.

The oxidative study was carried out in $30 \%(\mathrm{v} / \mathrm{v}) \mathrm{H}_{2} \mathrm{O}_{2}$ at room temperature for 7 days. Hydrolytic decomposition of the drug was carried out in $5 \mathrm{~N} \mathrm{HCl}$ and $2 \mathrm{~N} \mathrm{NaOH}$ at $80^{\circ} \mathrm{C}$ for $3 \mathrm{~h}$ and $1 \mathrm{~h}$, respectively, and in the water, refluxing at $80^{\circ} \mathrm{C}$ for $24 \mathrm{~h}$. Effect of dry heat (thermal degradation) and light (photodegradation) was studied on solid state. In case of thermal stress testing, the drug was sealed in glass vials and placed in a thermostatic block at $80^{\circ} \mathrm{C}$ for $1 \mathrm{~h}$. During photodegradation, the solid drug powder was exposed to UV light $(254 \mathrm{~nm})$ along with control samples (covered with aluminum foil). The same stress conditions were applied to placebo solution. All degradation samples after requisite exposure to stress conditions were diluted with methanol to obtain the concentration of individual drug as $60 \mu \mathrm{g} / \mathrm{ml}$

\section{Sample preparation}

A total of 20 tablets of DCV were weighed and average weight was calculated for each tablet. Then, the tablets were powdered and weight equivalent to one tablet $(60 \mathrm{mg}$ ) was measured. It was transferred into a $100 \mathrm{ml}$ volumetric flask; $50 \mathrm{ml}$ of the mobile phase was added, sonicated for 25 min. Final volume was made with the mobile phase and filtered. $1 \mathrm{ml}$ was pipetted out from the filtered solution into a $10 \mathrm{ml}$ volumetric flask and final volume was made with the mobile phase.

\section{RESULTS AND DISCUSSION}

\section{Optimization of LC-MS conditions}

The main aim of this work was to separate DCV and its DPs. During the optimization process, preliminary experiments were carried out on HPLC using Kromasil C18 column $(250 \mathrm{~mm} \times 4.6 \mathrm{~mm} \times 5 \mu \mathrm{m})$. For the selection of mobile phase, various mobile phases such as methanol/ water and acetonitrile/water in different proportions were tried in an isocratic mode. The peaks corresponding to drug and DPs did not resolve completely and tailing was noticed. To get acceptable separation between the drug and its DP, ammonium acetate buffer was used. Further studies were carried out using varied proportions of acetonitrile (a) and ammonium acetate buffer (b). To optimize the method, $\mathrm{pH}$ of the buffer, flow rate, and composition of the mobile phase were systematically varied. Finally, we achieved good resolution of peaks with acceptable shape with ammonium acetate buffer $(\mathrm{pH} 4.5)$ and acetonitrile in a ratio of 50:50, in an isocratic mode. The flow rate $0.8 \mathrm{ml} / \mathrm{min}$, column temperature $25^{\circ} \mathrm{C}$, at a wavelength of $315 \mathrm{~nm}$, and injection volume $20 \mu \mathrm{l}$ were found to be suitable to achieve the separation of DCV and its DP (Fig. 2). As the above-mentioned good resolution of the drug and its DP was observed with C-18 column, the same column was used for throughout HPLC analysis. The developed method possesses the advantages of simplicity as well as rapid determination.

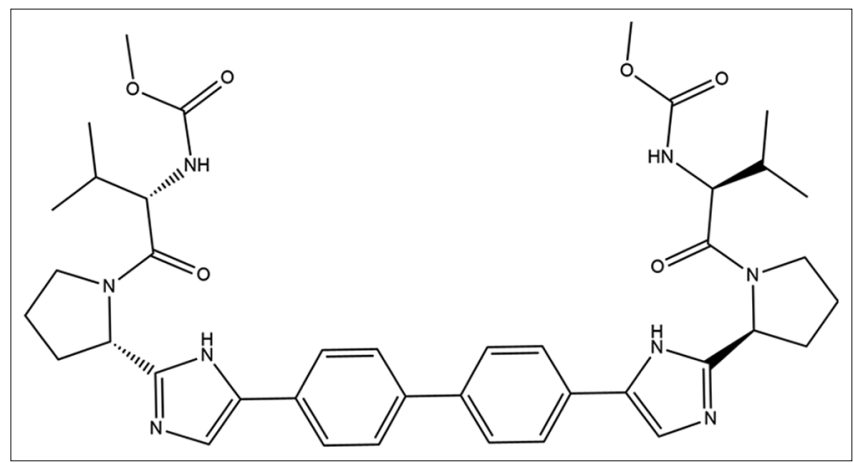

Fig. 1: Chemical structure of daclatasvir

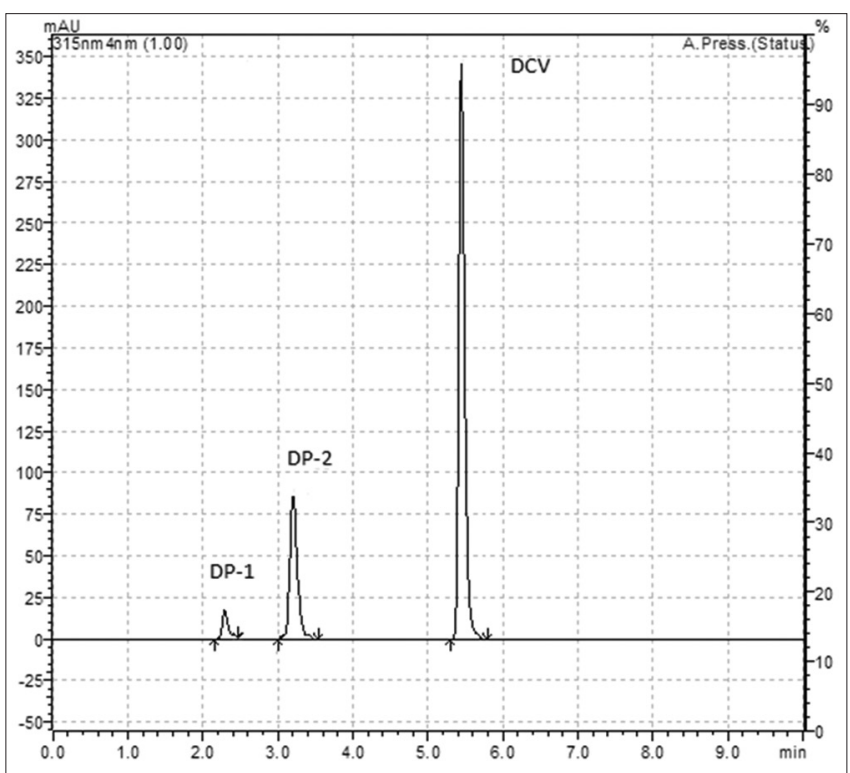

Fig. 2: Chromatogram shows the separation of degradation products (DP-1 to DP-2) and daclatasvir in the mixture of stressed sample 
The optimized LC method was validated with respect to various parameters outlined in the ICH guideline [12] and was extended to LC-MS/MS studies. The chromatographic conditions used for LC-MS analysis were similar to that of the LC-PDA analyses, except injection volume was $0.20 \mu \mathrm{l}$.

\section{Method validation}

Specificity

The ability of the analytical method to measure the analyte concentration accurately in the presence of all potential DPs is known as specificity. The specificity of the developed method toward the drug was studied by the determination of purity for drug peak in stressed sample. The study of resolution factor was also done and was found to be $>2$. The drug and DP peaks were found to be pure from peak purity data. Peak purity and resolution factor data are given in Table 1.

\section{Linearity}

Linearity test solutions were prepared at seven concentration levels from stock solution $(30,60,90,120,150,180$, and $210 \mu \mathrm{g} / \mathrm{ml})$. The least squares linear regression analysis was performed to study the relationship between peak area and concentration. The calibration curve was drawn by plotting DCV average area for triplicate injections and the concentration expressed as a percentage. Good linearity was observed in the concentration range from 30 to $210 \mu \mathrm{g} / \mathrm{ml}$ of DCV. The data were subjected to statistical analysis using a linear regression model, the linear regression equation and correlation coefficient $\left(r^{2}\right)$ were $y=59136 x-100914$ and 0.9999 , respectively. These results indicate good linearity. The LOD and LOQ were measured at a signalto-noise ratio of 3:1 and 10:1, respectively. The LOD and LOQ were $1.21 \mu \mathrm{g} / \mathrm{ml}$ and $3.68 \mu \mathrm{g} / \mathrm{ml}$

\section{Precision}

The precision of the method was performed by intraday and interday precision studies. Intraday precision studies were performed by injecting the drug in hexaplicate on the same day. Interday precision was checked by repeating the studies on 3 different days.

The results of intraday and interday precision studies are presented in Table 2. The RSD values for intraday and interday precision studies were $<0.35$ and 0.70 , respectively, indicating that developed method is precise.

\section{Accuracy}

Accuracy of the method was studied by employing the standard addition method, at three different levels $(80 \%, 100 \%$, and $120 \%)$. The recovery studies were carried out in triplicate and from the difference between peak areas of fortified and unfortified samples of DCV determine the

Table 1: HPLC system suitability parameters

\begin{tabular}{lllll}
\hline Code & $\mathbf{R T}$ & $\mathbf{N}$ & $\mathbf{T}_{\mathbf{f}}$ & $\mathbf{R}_{\mathbf{s}}$ \\
\hline DP-1 & 2.3 & 2271 & 1.34 & 2.807 \\
DP-2 & 3.1 & 3005 & 1.32 & 4.210 \\
Daclatasvir & 5.5 & 6142 & 1.29 & - \\
\hline
\end{tabular}

RT: Retention time, N: Number of theoretical plates, $\mathrm{T}_{\mathrm{f}}$ USP tailing factor $\mathrm{R}_{\mathrm{s}}$ : USP resolution, DP: Degradation product, HPLC: High-performance liquid chromatography

Table 2: Precision studies

\begin{tabular}{|c|c|c|}
\hline \multirow[t]{2}{*}{$\begin{array}{l}\text { Concentration } \\
\text { taken }(\mu \mathrm{g} / \mathrm{ml})\end{array}$} & \multicolumn{2}{|c|}{$\begin{array}{l}\text { Measured concentration }(\mu \mathrm{g} / \mathrm{ml}) \pm \mathrm{SD} \text {, } \\
\text { RSD }(\%)\end{array}$} \\
\hline & $\begin{array}{l}\text { Intraday } \\
\text { precision }(n=6)\end{array}$ & $\begin{array}{l}\text { Interday } \\
\text { precision }(n=3)\end{array}$ \\
\hline 60 & $60.48 \pm 0.183,0.302$ & $59.988 \pm 0.413,0.688$ \\
\hline
\end{tabular}

SD: Standard deviation, \% RSD: Percentage relative standard deviation, $\mathrm{n}$ : Number of injections percentage of added drug at each level. Good recoveries (100.5-102.73) were obtained at each added concentration, indicating that the method was accurate. Table 3 represents the percentage recovery for the drug.

\section{Robustness}

The robustness of the method was determined by purposely altering experimental condition. Three parameters selected were flow rate $( \pm 0.1 \mathrm{ml} / \mathrm{min})$, the wavelength change $( \pm 2 \mathrm{~nm})$, and change in acetonitrile content in the mobile phase $( \pm 2 \%)$. While altering one set of condition, the other conditions were held constant at the optimum values. In all the

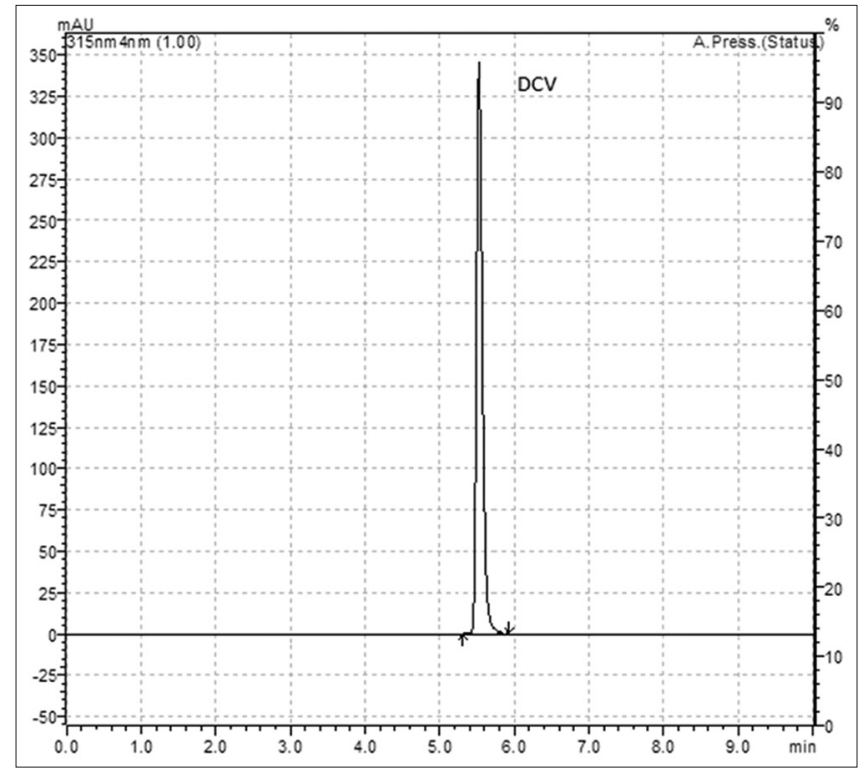

Fig. 3: Chromatogram of tablet formulation of daclatasvir

Table 3: Recovery studies

\begin{tabular}{lll}
\hline $\begin{array}{l}\text { Spiked } \\
\text { concentration } \\
(\boldsymbol{\mu g} / \mathrm{ml})\end{array}$ & $\begin{array}{l}\text { Measured } \\
\text { concentration }(\boldsymbol{\mu g} / \mathrm{ml})\end{array}$ & Recovery (\%) \\
$\mathbf{\pm}$ SD, RSD $(\%)$ & \\
\hline 40 & $40.8 \pm 0.046,0.156$ & 102 \\
60 & $61.64 \pm 0.187,0.317$ & 102.73 \\
80 & $78.66 \pm 0.238,0.265$ & 100.56 \\
\hline
\end{tabular}

$\mathrm{n}=3$, SD: Standard deviation, \% RSD: Percentage relative standard deviation

Table 4: Robustness results of DCV

\begin{tabular}{llll}
\hline Chromatographic changes & & & \\
\hline Factor & Level & $\mathbf{R T}$ & $\mathbf{T}_{\mathrm{f}}$ \\
\hline A. Flow rate (ml/min) & & & \\
0.7 & -0.1 & 5.62 & 1.29 \\
0.8 & 0 & 5.51 & 1.31 \\
0.9 & +0.1 & 5.42 & 1.30 \\
$\quad$ Mean \pm SD & & $5.517 \pm 0.10$ & $1.30 \pm 0.01$ \\
B. Wavelength change (nm) & & & \\
314 & -2 & 5.57 & 1.29 \\
316 & 0 & 5.65 & 1.30 \\
318 & +2 & 5.54 & 1.26 \\
Mean \pm SD & & $5.58 \pm 0.057$ & $1.28 \pm 0.021$ \\
C. Percentage of acetonitrile in & & & \\
mobile phase (v/v) & & & \\
48 & -2 & 5.65 & 1.31 \\
50 & 0 & 5.63 & 1.30 \\
52 & +2 & 5.60 & 1.28 \\
Mean $\pm \%$ SD & & $5.62 \pm 0.025$ & $1.29 \pm 0.015$ \\
\hline
\end{tabular}

$\mathrm{n}=3$, RT: Retention time, $\mathrm{T}_{\mathrm{f}}$ USP tailing factor, $\mathrm{n}$ : Number of injections, SD: Standard deviation, DCV: Daclatasvir 
Table 5: Optimized stress conditions for DCV

\begin{tabular}{|c|c|c|c|c|}
\hline Stressor & Concentration of stressor & Temperature and time & $\%$ assay of active substance & $\%$ degradation \\
\hline Acid & $5 \mathrm{~N} \mathrm{HCl}$ & $80^{\circ} \mathrm{C}$ for $4 \mathrm{~h}$ & 92.53 & 7.47 \\
\hline Alkali & $2 \mathrm{~N} \mathrm{NaOH}$ & $80^{\circ} \mathrm{C}$ for $1 \mathrm{~h}$ & 72.04 & 27.96 \\
\hline Oxide & $30 \% \mathrm{H}_{2} \mathrm{O}_{2}$ & RT for 7 days & 96.07 & 3.93 \\
\hline Neutral & $\mathrm{H}_{2} \mathrm{O}$ & $80^{\circ} \mathrm{C}$ for $24 \mathrm{~h}$ & 97.87 & 2.13 \\
\hline Heat & $80^{\circ} \mathrm{C}$ & $80^{\circ} \mathrm{C}$ for $1 \mathrm{~h}$ & 97.05 & 2.95 \\
\hline Photodegradation & UV (254 nm) & $24 \mathrm{~h}$ & 98.90 & 1.10 \\
\hline
\end{tabular}

DCV: Daclatasvir

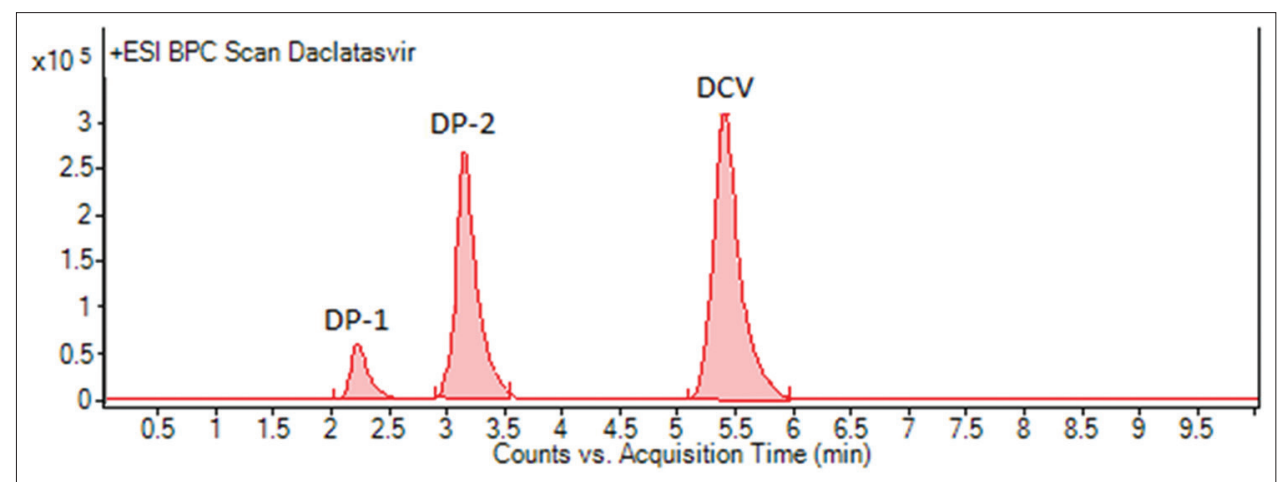

Fig. 4: Liquid chromatography-mass spectrometry chromatogram showing separation of daclatasvir and its degradation product 1 and 2 in the mixture of stressed samples

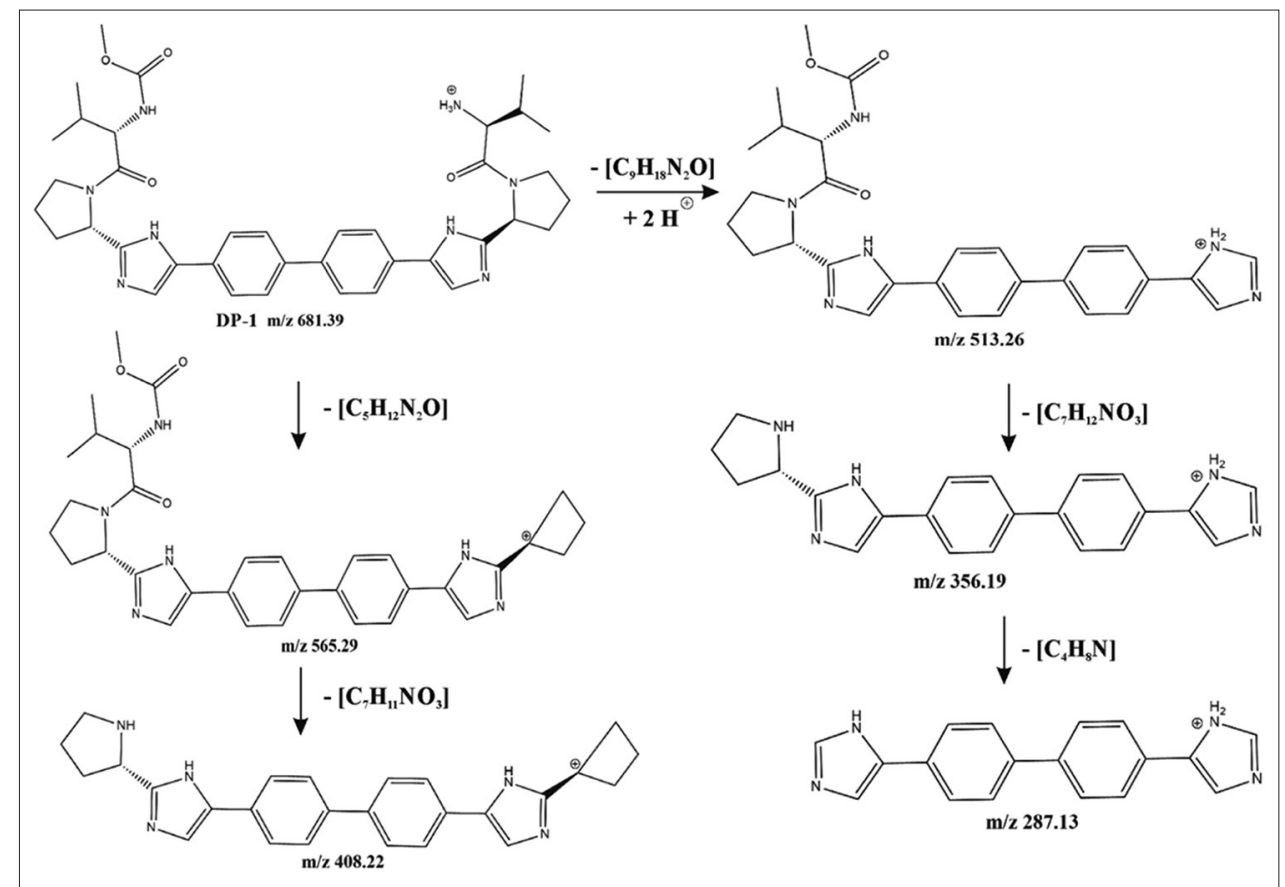

Scheme 1: Mass fragmentation pathway of degradation product-1

deliberately varied chromatographic conditions, no marked change in retention time and tailing factor of DCV is observed in Table 4.

\section{System suitability test}

The system suitability parameters with respect to resolution factor, theoretical plates, and tailing factor were calculated and are given in Table 1. It could be seen from the readings that the peaks of the drug and DP-1 and DP-2 were well resolved.

\section{Degradation behavior}

The drug was degraded in acidic hydrolytic condition $(5 \mathrm{~N})$ to $7.47 \%$ to form product 2 , whereas in alkali stress condition $(2 \mathrm{~N})$, the drug degraded to $28 \%$ to form products 1 and 2 . The DP 2 formed under both acidic and base hydrolytic conditions was overlapped in the chromatogram to show only one peak of product 2 .

The chromatogram of mixture of stressed sample showing separation of drug and its DP is shown in Fig. 2. The drug was stable under all other stress conditions including heating in water, oxidation, photoexposure of solid drug, and dry heating at $80^{\circ} \mathrm{C}$ as shown in Table 5 .

Study of the stability of commercial tablets

To study the assay content of DCV, tablets were prepared in house $(60 \mathrm{mg})$ and were analyzed by the proposed method after exposure 
to accelerated storage condition (i.e., $40^{\circ} \mathrm{C} / 75 \% \mathrm{RH}$ ). The peak was observed at retention time $5.58 \mathrm{~min}$ for the drug in the chromatogram of the drug samples extracted from tablets and no additional peak was found (Fig. 3). Experimental results are shown in Table 6 indicating that amount of DCV in tablets (\% label claim) was in good agreement with the label claims, suggesting that there was no interference from any excipients, which are normally present in tablets and good quality packaging material was used. The statistical analysis is presented in Table 7.

\section{Mass fragmentation pathway of the DPs}

The mass fragmentation pathway was established from the results of LC-ESI-MS in positive mode. The positive ion MS spectrum of DCV exhibits a parent ion peak $[\mathrm{M}+\mathrm{H}]^{+}$of $739.38(\mathrm{~m} / \mathrm{z})$ which corresponds to the theoretical value of molecular mass of DCV, i.e., $738.89 \mathrm{~g} / \mathrm{mol}$.

Table 6: Results of analysis of tablet formulation

\begin{tabular}{lll}
\hline Tablet strength $\mathbf{6 0} \mathbf{~ m g}$ & & \\
\hline $\begin{array}{l}\text { Weight of tablet powder } \\
\text { taken } \mathbf{( m g )}\end{array}$ & $\begin{array}{l}\text { Amount of drug } \\
\text { estimated (mg/capsule) }\end{array}$ & $\begin{array}{l}\text { \% label } \\
\text { claim }\end{array}$ \\
\hline 60 & 61.14 & 101.90 \\
60 & 60.90 & 101.49 \\
60 & 61.24 & 102.06 \\
60 & 61.33 & 102.21 \\
60 & 61.03 & 101.71 \\
60 & 60.88 & 101.47 \\
\hline
\end{tabular}

To characterize the DPs, the stressed solution of DCV was subjected to LC-MS analysis. The resulted LC-MS chromatogram is shown in Fig. 4.

\section{Postulated structure of DPs}

$D P-1(\mathrm{~m} / \mathrm{z}$ 681.39)

The LC-ESI-MS of the base hydrolytic degraded sample showed a parent ion peak at $681.39 \mathrm{~m} / \mathrm{z}$ which supports the proposed structure of DP-1 (Scheme 1). Probably, the product is $(S)-1-\left((S)-2-\left(5-\left(4^{\prime}-(2-((S)-1-((S)-\right.\right.\right.$ 2-((methoxycarbonyl)amino)-3-methylbutanoyl)pyrrolidin-2-yl)-1Himidazol-5-yl)-[1,1'-biphenyl]-4-yl)-1H-imidazol-2-yl)pyrrolidin-1-yl) -3-methyl-1-oxobutan-2-aminium.

ESI-MS ${ }^{2}$ of $[\mathrm{M}+\mathrm{H}]^{+}$ion at $\mathrm{m} / \mathrm{z} 681.39$ shows abundant fragment ions at $\mathrm{m} / \mathrm{z} 513.26$ (loss of $\mathrm{C}_{9} \mathrm{H}_{18} \mathrm{~N}_{2} \mathrm{O}$, addition of $2 \mathrm{H}^{+}$from $\mathrm{m} / \mathrm{z}$ 681.39), and low abundance ion at $\mathrm{m} / \mathrm{z} 565.29$ (loss of $\mathrm{C}_{5} \mathrm{H}_{12} \mathrm{~N}_{2} \mathrm{O}$ from $\mathrm{m} / \mathrm{z}$ 681.39), $\mathrm{m} / \mathrm{z} 408.22$ (loss of $\mathrm{C}_{7} \mathrm{H}_{11} \mathrm{NO}_{3}$ from $\mathrm{m} / \mathrm{z} 565.29$ ), $\mathrm{m} / \mathrm{z} 356.19$ (loss of $\mathrm{C}_{7} \mathrm{H}_{12} \mathrm{NO}_{3}$ from $\mathrm{m} / \mathrm{z} 513.26$ ), and $\mathrm{m} / \mathrm{z} 287.13$ (loss of $\mathrm{C}_{4} \mathrm{H}_{8} \mathrm{~N}$ from $\mathrm{m} / \mathrm{z}$ 356.19) (Fig. 5 and Scheme 1).

\section{Postulated structure of DP-2 (m/z 582.32)}

The product was exclusively seen in the +ESI mode (Fig. 4). DP-2 was observed after acid and base hydrolysis of the drug. The product is (S)-2(5-(4'-(2-((S)-1-((S)-2-((methoxycarbonyl)amino)-3-methylbutanoyl) pyrrolidin-2-yl)-1H-imidazol-5-yl)-[1,1'-biphenyl]-4-yl)-1H-imidazol-2 yl)pyrrolidin-1-ium.

The ESI-MS ${ }^{2}$ of $[\mathrm{M}+\mathrm{H}]^{+}$ion at $\mathrm{m} / \mathrm{z} 582.32$ shows abundant fragment ion at $\mathrm{m} / \mathrm{z} 513.26$ (loss of $\mathrm{C}_{4} \mathrm{H}_{9} \mathrm{~N}$, addition of $2 \mathrm{H}^{+}$from $\mathrm{m} / \mathrm{z} 582.32$ ),

Table 7: Statistical validation of analysis of capsule formulation

\begin{tabular}{|c|c|c|c|c|c|}
\hline Drug & Amount of drug estimated (mg/tablet) & \% label claim* & SD & CV & SE \\
\hline Daclatasvir & 61.086 & 101.81 & 0.304 & 0.309 & 0.074 \\
\hline
\end{tabular}

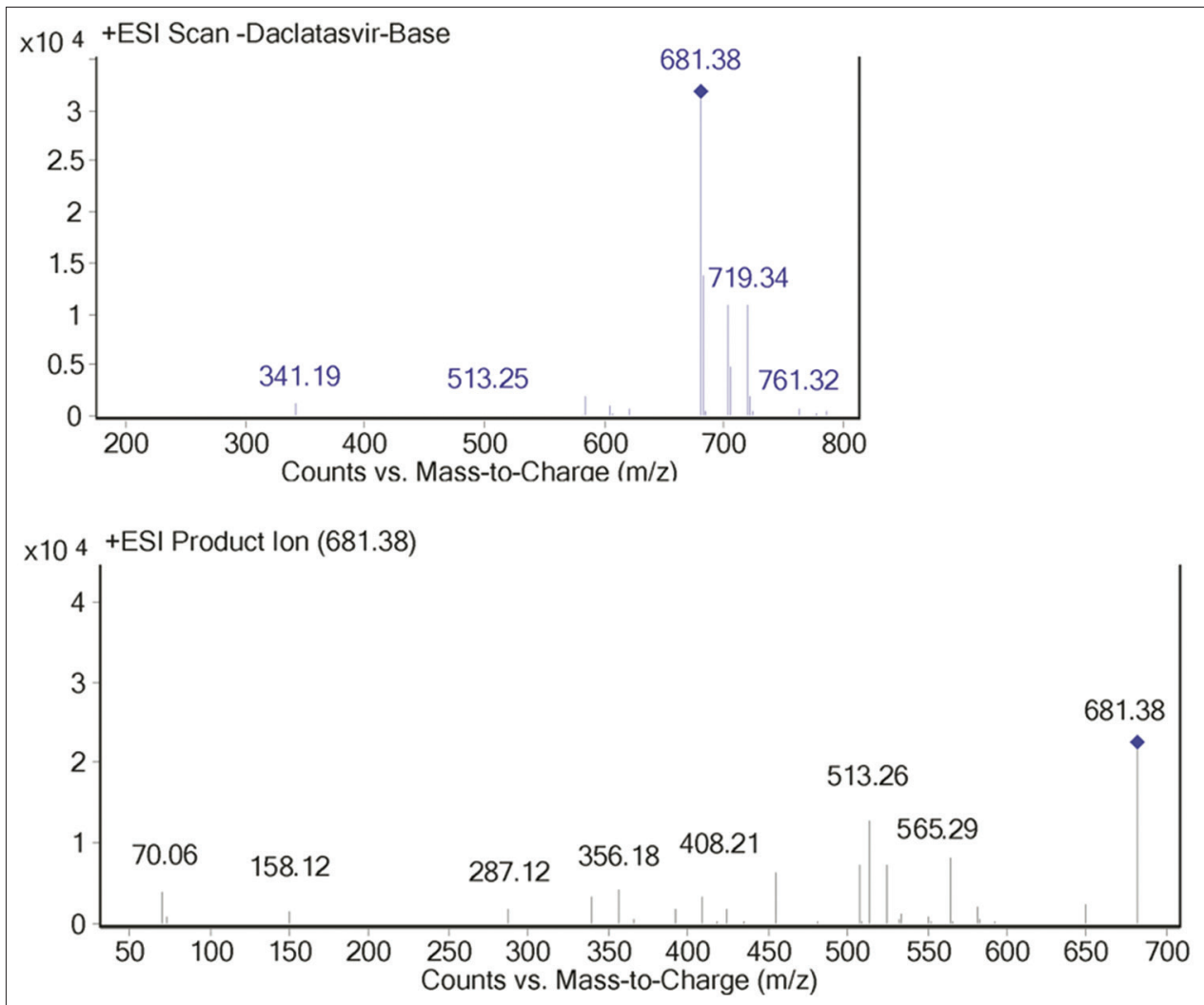

Fig. 5: Liquid chromatography-mass spectrometry and tandem mass spectrometry spectra of degradation product-1, respectively, +electrospray ionization mode 


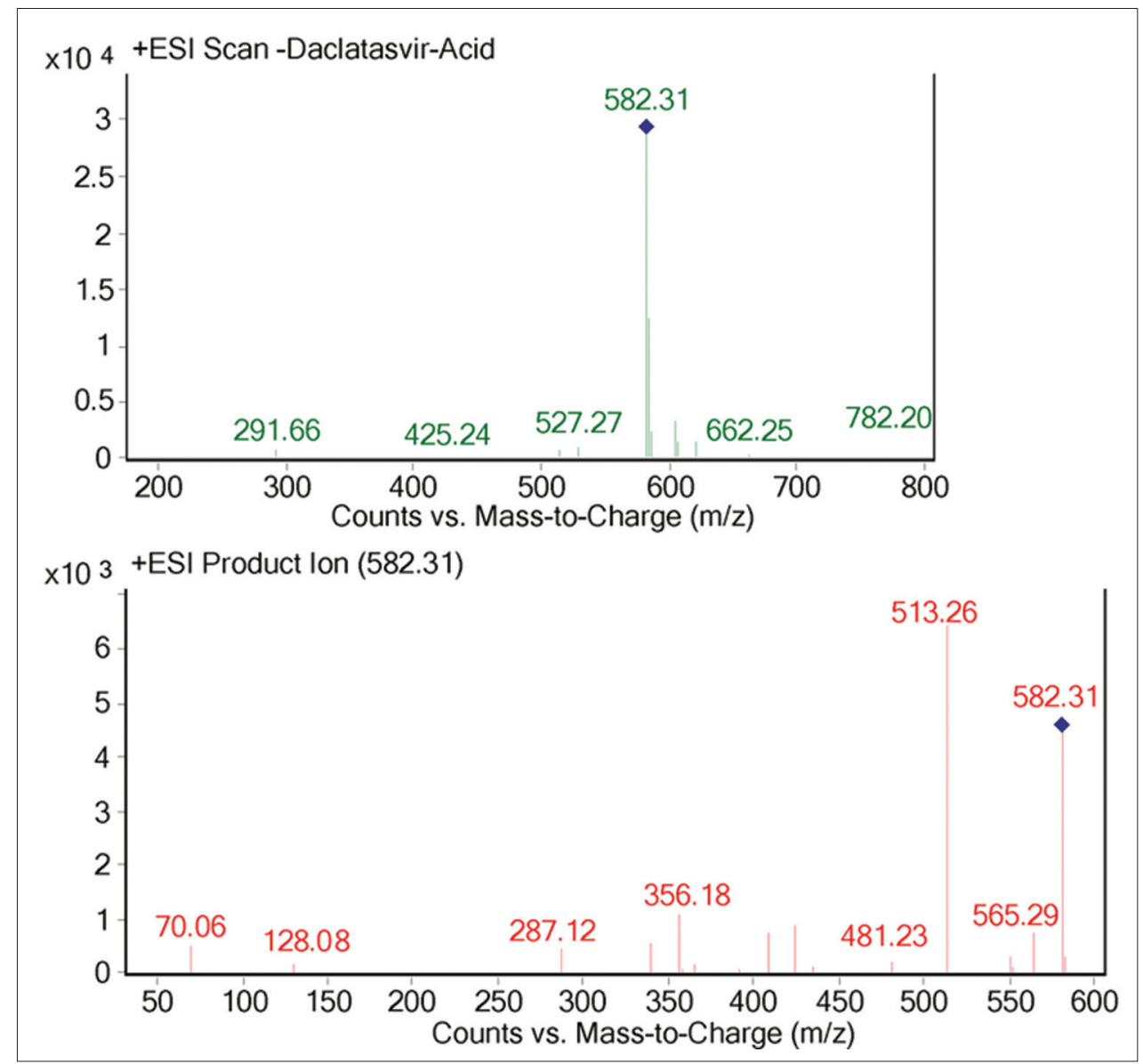

Fig. 6: Liquid chromatography-mass spectrometry and tandem mass spectrometry spectra of degradation product-2, respectively, +electrospray ionization mode

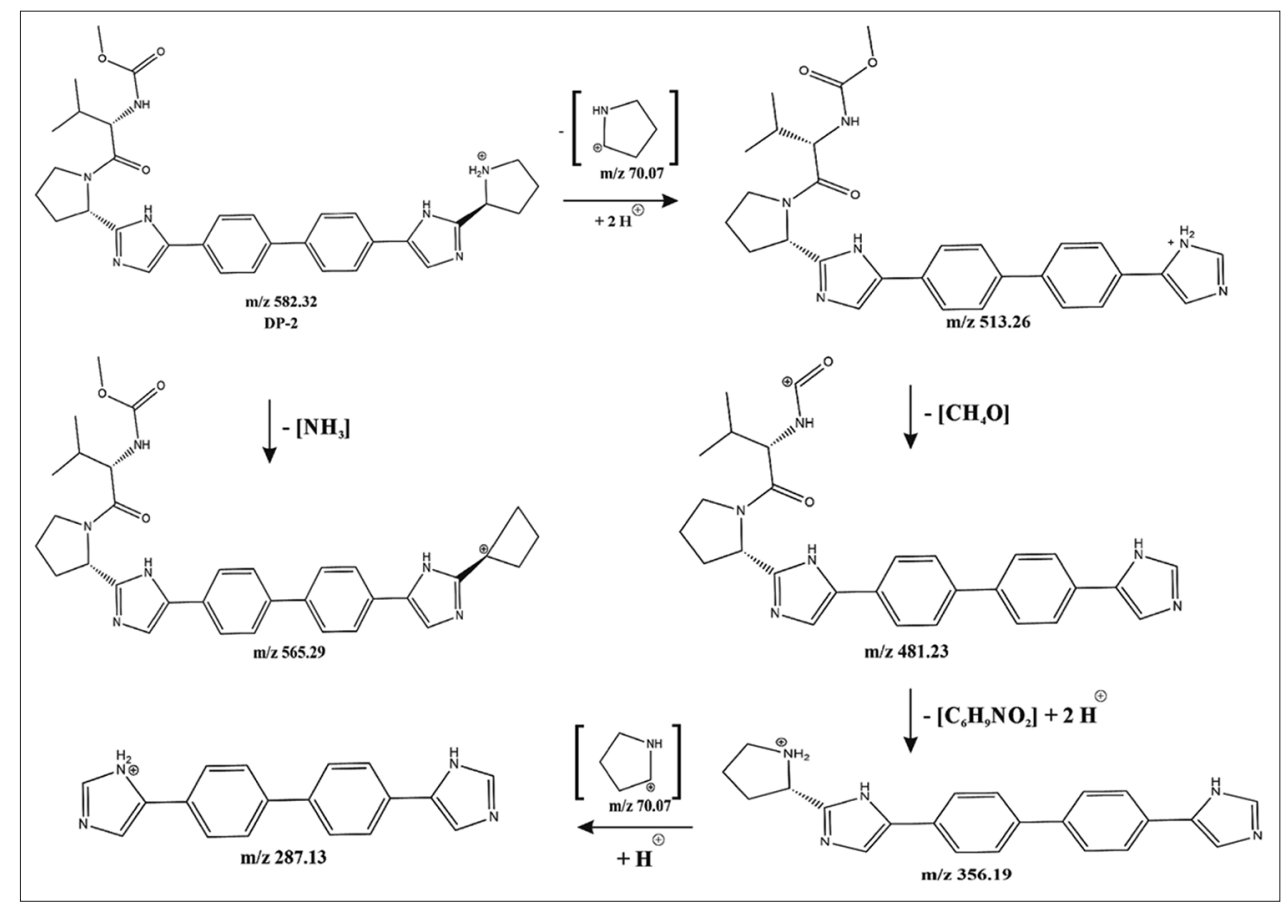

Scheme 2: Mass fragmentation pathway of degradation product-2

along with its low abundance ion at $\mathrm{m} / \mathrm{z} 70.07$ (loss of $\mathrm{C}_{29} \mathrm{H}_{33} \mathrm{~N}_{6} \mathrm{O}_{3}{ }^{+}$, from $\mathrm{m} / \mathrm{z}$ 582.32), low abundance at $\mathrm{m} / \mathrm{z} 565.29$ (loss of $\mathrm{NH}_{3}$, from $\mathrm{m} / \mathrm{z}$ 582.32) and, $\mathrm{m} / \mathrm{z} 481.23$ (loss of $\mathrm{CH}_{4} \mathrm{O}$, from $\mathrm{m} / \mathrm{z} 513.26$ ), $\mathrm{m} / \mathrm{z}$
356.19 (loss of $\mathrm{C}_{6} \mathrm{H}_{9} \mathrm{NO}_{2}$, addition of $2 \mathrm{H}^{+}$from $\mathrm{m} / \mathrm{z} 481.23$ ), and $\mathrm{m} / \mathrm{z}$ 287.13 (loss of $\mathrm{C}_{4} \mathrm{H}_{8} \mathrm{~N}$, addition of $\mathrm{H}^{+}$from $\mathrm{m} / \mathrm{z}$ 356.19) (Fig. 6 and Scheme 2). 


\section{CONCLUSION}

According to ICH guidelines, stress degradation studies on DCV were carried out to provide information regarding degradation behavior of the drug. The drug was susceptible to acid and base hydrolytic degradation, whereas it was stable in all other conditions. Two DPs were formed and separated in a single run by an isocratic RP-HPLC method. The product was a new DP and was not reported in literature. The developed method proved to be simple, accurate, precise, specific, and robust. It was successfully employed for the analysis of the tablet formulation stored under accelerated conditions of temperature and humidity. The DPs were characterized with the help of LC-MS/MS and complete fragmentation pathways are proposed and shown in Scheme 1 and Scheme 2, respectively. Characterized DPs can help to synthesize reference standards and to observe their presence in the stability samples. This study discovered the useful information which is not still reported in literature of DCV. The developed method was found to be less time consuming as the drug gets eluted at 5.54 RT (less time of analysis) and cost effective and may be more advantageous for routine analysis of the drug in marketed formulation.

\section{ACKNOWLEDGMENT}

Authors are thankful to Smt. Kashibai Navale College of Pharmacy and Sinhgad Institute of Pharmacy (Pune, India) for providing necessary facilities to carry out the work. Authors are also thankful to Principal, Padm. Dr. D.Y. Patil Institute of Pharmaceutical Sciences and Research, Pune, and Venture Center (NCL, Pune, India).

\section{AUTHORS' CONTRIBUTIONS}

The research was proposed and designed by Dr. K. G. Bothara. The experimental work was carried out by Miss Snehal Warghade. The manuscript was drafted by Miss Snehal Warghade which was further edited by Dr. K. G. Bothara. Authors read and approved the final manuscript.

\section{CONFLICTS OF INTEREST}

The authors declare that there are no conflicts of interest in the present study.

\section{REFERENCES}

1. Boni C, Sundararajan R. Method development, validation and stability studies for determination of bumetanide in bulk and pharmaceutical dosage form by RP-UPLC. Int J Pharm Pharm Sci 2018;10:35-42.

2. International Conference on Harmonization: (ICH): Q1A(R2), Stability Testing of New Drug Substances and Products: IFPMA; 2003.

3. International Conference on Harmonization: (ICH): Q3A (R2), Impurities in New Drug; 2006.

4. Bakshi M, Singh S. Development of validated stability-indicating assay methods-critical review. J Pharm Biomed Anal 2002;28:1011-40.

5. Sawant S, Barge V. A validated stability indicating RP-HPLC method for satranidazole, identification and characterization of a photolytic degradation product of satranidazole using LC-APCI-ION TRAP-MS. Int J Pharm Pharm Sci 2014;6:621-5.

6. Smith MA, Regal RE, Mohammad RA. Daclatasvir: A NS5A replication complex inhibitor for hepatitis C infection. Ann Pharmacother 2016; 50:39-46.

7. Chakravarthy VA, Sailaja BB. Method development and validation of assay and dissolution methods for the estimation of daclatasvir in tablet dosage forms by reverse phase HPLC. Eur J Pharm Med Res 2016; 3:356-64.

8. Saleh H, Ragab GH, Othman MA. Stability indicating HPLC method development and validation for determination of daclatasvir in pure and tablets dosage forms. Indo Am J Pharm Sci 2017;3:1565-72.

9. Baker MM, El-Kafrawy DS, Mahrous MS, Belal TS. Validated stabilityindicating HPLC-DAD method for determination of the recently approved hepatitis C antiviral agent daclatasvir. Ann Pharm Fr 2017; $75: 176-84$

10. Hassib ST, Taha EA, Elkady EF, Barakat GH. Reversed-phase liquid chromatographicmethodfordetermination ofdaclatasvirdihydrochloride and study of its degradation behavior. Chromatographia 2017; 80:1101-7.

11. Zaman B, Hassan W. Development of stability indicating HPLC-UV method for determination of daclatasvir and characterization of forced degradation products. Chromatographia 2018;81:785-97.

12. International Conference on Harmonization: ICH: Q2 (R1), Validation of Analytical Procedures: Text and Methodology; 1995.

13. International Conference on Harmonization ICH: Q2B, Analytical Validation-Methodology; 1996. p. 24

14. International Conference on Harmonization ICH: Q2A, Text on Validation of Analytical Procedure; 1994. p. 22 